\title{
TINJAUAN KELAYAKAN RUANG HENTI KHUSUS (RHK) BERDASARKAN TINGKAT KETERISIAN DI SIMPANG BERSINYAL KOTA BANDA ACEH
}

\author{
Herri Arnanda ${ }^{1)}$, Renni Anggraini ${ }^{2)}$, Yusria Darma ${ }^{3)}$ \\ ${ }^{1)}$ Magister Teknik Sipil, Fakultas Teknik, Universitas Syiah Kuala, Banda Aceh \\ 2), 3) Jurusan Teknik Sipil, Fakultas Teknik, Universitas Syiah Kuala, Banda Aceh \\ Corresponding author email: heriarnanda@gmail.com
}

DOI: http://dx.doi.org/10.29103/tj.v9i2.199

(Received: April 2019 / Revised: May 2019 / Accepted: June 2019)

\begin{abstract}
Abstrak
Simpang bersinyal merupakan suatu elemen yang cukup penting dalam sistem transportasi di kota besar seperti Simpang Jambo Tape di Kota Banda Aceh. Simpang Jambo Tape merupakan salah satu dari jaringan jalan yang menghubungkan beberapa tempat penting yang ada di Kota Banda Aceh, seperti pertokoan, perkantoran, sekolah, rumah sakit dan pemukiman penduduk. Hal ini menyebabkan aktifitas lalu lintas pada simpang tersebut sangat tinggi, sehingga dapat mengakibatkan kemacetan dan tundaan pada beberapa kaki persimpangan. Salah satu masalah yang dihadapi simpang bersinyal ialah kurang efektifnya prasarana sehingga menjadi tidak layak prasaran tersebut yang telah dibangun oleh pemerintah setempat untuk masyarakat dalam menggunakan prasarana transportasi itu sendiri seperti Ruang Henti Khusus (RHK). Karna prasarana yang dibangun seperti RHK tersebut untuk dapat melancarkan arus lalu lintas di simpang. Tujuan penelitian ini adalah untuk mengetahui kelayakan RHK simpang bersinyal Simpang Jambo Tape di Kota Banda Aceh. Metode yang digunakan berupa perbandingan pada tahun 2013 sebelum adanya RHK dan tahun 2018 setelah adanya RHK. Untuk kelayakan RHK berdasarkan tingkat keterisian dengan metode dari Balai Teknik Lalu Lintas dan Lingkungan Jalan (2012) yang dihubungkan dengan kinerja simpang bersinyal dari metode dari PKJI 2014. Hasil dari penelitian didapat kelayakan RHK yang dilihat dari tingkat keterisian ialah rata-rata 50\% yang artinya kurang berhasil diterapkan sedangkan untuk kinerja simpang bersinyal semakin bertambah di mana didapat nilainya $\geq 0,85$ yang artinya arus lalu lintas tersebut macet. Sehingga dari hasil tersebut didapat fungsi RHK tidak dapat membuat kinerja simpang bersinyal menjadi baik sehingga RHK yang ada di Simpang Jambo Tape tidak layak. Untuk itu diharapkan kepada Pemerintah setempat dengan hasil ini dapat menjadi acuan dalam evaluasi RHK di Simpang Jambo Tape sehingga kelayakan Zona RHK tersebut menjadi baik.
\end{abstract}

Kata kunci: sepeda motor, kapasitas, derajat kejenuhan, tingkat keterisian RHK, kinerja simpang bersinyal.

\begin{abstract}
Signalized intersections are an important element in transportation systems in large cities such as Jambo Tape Intersection in Banda Aceh City. Jambo Tape intersection is one of the road networks that connect several important places in the city of Banda Aceh, such as shops, offices, schools, hospitals and residential areas. This causes the traffic activity at the intersection to be very high, so it can lead to congestion and delays at several crossing junctions. One of the problems faced by signalized
\end{abstract}

Tinjauan kelayakan ruang henti khusus (rhk) berdasarkan tingkat keterisian di Simpang 
intersections is the lack of effectiveness of the infrastructure so that the infrastructure is not feasible that has been built by the local government for the community to use the transportation infrastructure itself such as the Special Stop Room (RHK). Because the infrastructure is built like the RHK to be able to smoothen the flow of traffic at the intersection, the purpose of this study was to determine the feasibility of RHK signaling intersections namely Jambo Tape Intersection in Banda Aceh City. The method used was a comparison in 2013 before the presence of RHK and in 2018 after the presence of RHK on the Jambo Tape Intersection. For the feasibility of RHK based on the level of completeness with the method from the Hall of Traffic Engineering and Road Environment (2012) which was associated with the performance of signalized intersections of the methods of the 2014 PKJI. The results obtained from RHK feasibility seen from the level of filling were $50 \%$ which means less unsuccessful when it applied while for the performance of the signaling intersection is increasing with the value is $\geq 0.85$ that means the traffic flow is jammed. The conclusion is that the RHK function does not make signal intersection performance good so the RHK in Jambo Tape Intersection is not feasible. For this reason, it is expected that the local government can produce a reference in the RHK evaluation at Jambo Tape intersection so that the feasibility of the RHK Zone is good

Keywords: motorcycle, capacity, degree of saturation, performance Level of filling in RHK signalized intersection

\section{Latar Belakang}

Transportasi merupakan salah satu aspek penting dalam kehidupan manusia karena transportasi berkontribusi besar pada kehidupan dalam kaitannya dengan aktivitas manusia sehari-hari. Banda Aceh sebagai Ibu Kota Provinsi Aceh secara keseluruhan untuk kondisi sarana dan prasarana transportasi sudah cukup memadai untuk ukuran kota sedang (Pemerintah Kota Banda Aceh, 2017). Salah satu permasalahan yang dihadapi Kota Banda Aceh adalah kurangnya efektif prasarana yang dibangun oleh pemerintah setempat dan pemahaman masyarakat dalam memakai sarana dan prasarana di bidang lalu lintas. Faktor penting untuk mencapai sistem prasarana transportasi darat yang baik adalah kemampuan dari suatu jalan dalam melayani arus lalu lintas, khususnya kemampuan dari suatu simpang sebagai salah satu bagian dari suatu sistem jalan secara keseluruhan. Sehingga salah satu prasarana yang dibangun oleh pemerintah ialah zona Ruang Henti Khusus (RHK) sesuai dengan surat edaran Menteri Pekerjaan Umum dan Perumahan Rakyat Nomor 52/SE/M/2015 tentang Pedoman Perancangan Ruang Henti Khusus (RHK) Sepeda Motor Pada Simpang Bersinyal di Kawasan Perkotaan dimana menjadi acuan dalam menetapkan ketentuan dan prosedur tentang tata cara perancangan RHK yang meliputi syarat geometrik, syarat kondisi lalu lintas dan perancangan teknis RHK. RHK itu sendiri merupakan tempat pemisahan ruang tunggu sepeda motor dengan kendaraan roda empat di suatu persimpangan sehingga ketika saat fase hijau arus kendaraan bisa menjadi lebih teratur dan tertib. Dengan adanya RHK pada simpang bersinyal maka diharapkan dapat meminimalisir konflik lalu lintas dan mengantisipasi kemacetan dengan memprioritaskan sepeda motor di lajur depan pemberhentian lampu lalu lintas.

Adanya RHK pada beberapa simpang bersinyal di Kota Banda Aceh yang dibangun pada tahun 2017 oleh pemerintah belum dapat diketahui efektivitasnya terhadap kinerja simpang itu sendiri. Simpang Jambo Tape yang merupakan salah satu simpang bersinyal yang tergolong daerah komersil dan akses jalan kawasan 
berbagai aktivitas masyarakat seperti pendidikan, kantor, rumah sakit dan perumahan. Oleh karena itu perlu pada penelitian ini akan dilakukan tinjauan kelayakan zona RHK sepeda motor dengan sebelum adanya zona RHK pada simpang bersinyal di Kota Banda Aceh.

\section{Metode Penelitian}

\subsection{Pengumpulan Data}

Penelitian ini fokus pada dua situasi, yaitu kondisi sebelum adanya RHK pada tahun 2013 yang datanya bersumber dari Dinas Perhubungan Aceh serta sesudah adanya RHK yaitu tahun 2018. Pengumpulan data yaitu melakukan pengukuran geometrik lokasi penelitian, dengan cara mengukur memanjang dan melintang dari jalan (Bukhari dan Sofyan, 2004). Lalu pengamatan terhadap volume lalu lintas bertujuan untuk mendapatkan besarnya volume lalu lintas yang melewati pada setiap simpang dan yang berhenti di zona Ruang Henti Khusus sepeda motor pada Simpang Jambo Tape yang akan diteliti. Pengamatan hanya meliputi pada jam-jam puncak yaitu pagi hari antara pukul 07.00-09.00 wib, siang hari yaitu antara pukul 12.00-14.00 WIB, dan sore hari antara pukul 16.00 - 18.00 WIB yang diasumsikan bahwa periode waktu tersebut intensitas peningkatan volume kendaraan dengan interval waktu pengamatan selama 15 menit yang kemudian direkapitulasikan per jam untuk keperluan perhitungan. Untuk lokasi penelitian dilakukan pada simpang bersinyal yaitu Simpang Jambo Tape seperti diperlihatkan pada Gambar 1.

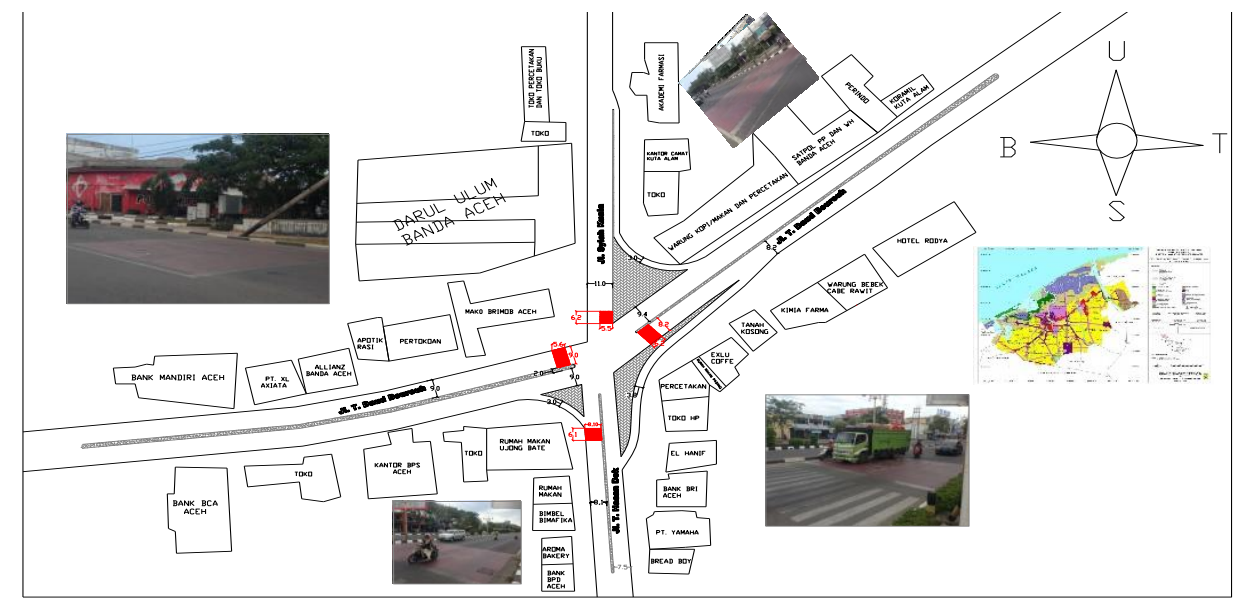

Gambar 1 Sketsa Simpang Jambo Tape

1

\subsection{Analisis Data}

Data terbagi dua yaitu data sekunder yang didapat dari Dinas Perhubungan Aceh pada tahun 2013 dan data primer dari lapangan. Kedua data tersebut akan dilakukan perbandingan dimana data tahun 2013 saat dimana belum adanya zona RHK lalu tahun 2018 ketika sudah adanya zona RHK. Pengolahan data dilakukan setelah data-data hasil pengamatan di lapangan telah direkapitulasi berdasarkan jumlah kendaraan dengan masing-masing jenisnya, dikalikan dengan angka 
ekivalensi kendaraan ringan (EKR) untuk diubah kedalam waktu satu jam (skr/jam). Setelah didapat nilai arus lalu lintas dan dibagi dengan nilai kapasitas jalan maka diperoleh nilai derajat kejenuhan (DS). Derajat kejenuhan digunakan sebagai faktor utama dalam penentuan tingkat kinerja simpang bersinyal dengan nilai derajat kejenuhan tidak boleh melebihi 0,85 (PKJI, 2014). Apabila nilai derajat kejenuhan melebihi 0,85 (PKJI, 2014) maka ruas jalan tersebut memiliki tingkat kinerja simpang bersinyal yang buruk sehingga segmen jalan tersebut mempunyai masalah pada kapasitas yang dapat menyebabkan kemacetan dan sebaliknya apabila nilai derajat kejenuhan lebih rendah atau sama dengan 0,85 maka kinerja bersinyal tersebut masih baik.

Tabel 1 Data Sekunder dan Data Primer

\begin{tabular}{cccccccc}
\hline & & \multicolumn{3}{c}{$\begin{array}{c}\text { Sp. Jambo Tape(Data } \\
\text { Sekunder/Dinas Perhubungan Aceh) }\end{array}$} & \multicolumn{3}{c}{$\begin{array}{c}\text { Sp. Jambo Tape (Data } \\
\text { Primer/Lapangan) }\end{array}$} \\
\cline { 3 - 8 } No & Jenis & \multicolumn{3}{c}{ Tanggal/Tahun } & \multicolumn{3}{c}{ Tanggal/Tahun } \\
\cline { 3 - 8 } & Kend. & 27 Juni & 29 Juni & 02 Juli & 24 Juli & 21 Juli & 25 Juli \\
& & 2013 & 2013 & 2013 & 2018 & 2018 & 2018 \\
\hline 1 & SM & 29.958 & 23.844 & 30.695 & 18.068 & 12.787 & 18.083 \\
2 & KR & 12.292 & 10.199 & 13.174 & 6.939 & 9.028 & 9.227 \\
3 & KB & 1.04 & 369 & 701 & 101 & 122 & 119 \\
\hline \multicolumn{2}{c}{ Jumlah } & 43.29 & 34.412 & 44.57 & 25.108 & 21.937 & 27.429 \\
\hline
\end{tabular}

Sedangkan untuk mencari kelayakan RHK yaitu jumlah volume sepeda motor yang berada pada Ruang Henti Khusus Sepeda motor pada fase merah akan dibagi dengan Ruang Henti Khusus sehingga akan didapat berapa persen kelayakan tingkat keterisian ruang henti khusus itu sendiri (Kementerian Pekerjaan Umum,dan Perumahan Rakyat, 2015). Kelayakan RHK dilihat dari berapa persen keterisian yang ditampung zona RHK oleh sepeda motor pada setiap simpang Simpang Jambo Tape. Sehingga bila kelayakan itu berhasil diterapkan maka fungsi dari RHK itu layak keberadaannya karena dapat meningkatkan kinerja simpang bersinyal yaitu Simpang Jambo Tape menjadi baik. Dari hasil tersebut nantinya akan menjadi pendukung untuk kelayakan zona RHK sepeda motor berdasarkan tingkat keterisian di Simpang Jambo Tape di Kota Banda Aceh.

\subsection{Tahapan Penelitian}

Penelitian dilakukan pada Simpang Jambo Tape di Kota Banda Aceh. Dimana tinjauan yang diteliti adalah kelayakan zona RHK terhadap kinerja simpang bersinyal. Karena fungsi dibangunnya RHK ialah memperbaiki kinerja persimpangan jalan perkotaan dengan biaya yang rendah, mengurangi konflik lalu lintas sepeda motor dengan kendaraan lain dan melancarkan arus lalu lintas dan mempercepat aliran arus lalu lintas di persimpangan (Dinas Perhubungan Kota Banda Aceh, 2017). Permasalahan yang terjadi di Kota Banda Aceh secara umum dan visual adalah kurangnya efektif prasarana yang dibangun oleh pemerintah setempat. Maka dengan permasalahan tersebut maka dilakukan penelitian dalam 
mencari kelayakan RHK pada simpang Jambo Kota Banda Aceh berdasarkan ruang keterisian. Literatur-literatur yang diambil terdiri dari dua yaitu untuk kinerja persimpangan bersinyal bersumber dari Modul Panduan Kapasitas Jalan Indonesia, Departemen Pekerjaan Umum (PKJI, 2014) dari penyempurnaan modul sebelumnya yaitu Manual Kapasitas Jalan Indonesia, Kementerian Pekerjaan Umum dan Perumahan Rakyat (MKJI, 1997) sedangkan kelayakan RHK berdasarkan ruang keterisian berdasarkan surat edaran Menteri Pekerjaan Umum dan Perumahan Rakyat Nomor 52/SE/M/2015 tentang Pedoman Perancangan Ruang Henti Khusus (RHK) Kementerian Pekerjaan Umum dan Perumahan Rakyat (2015).

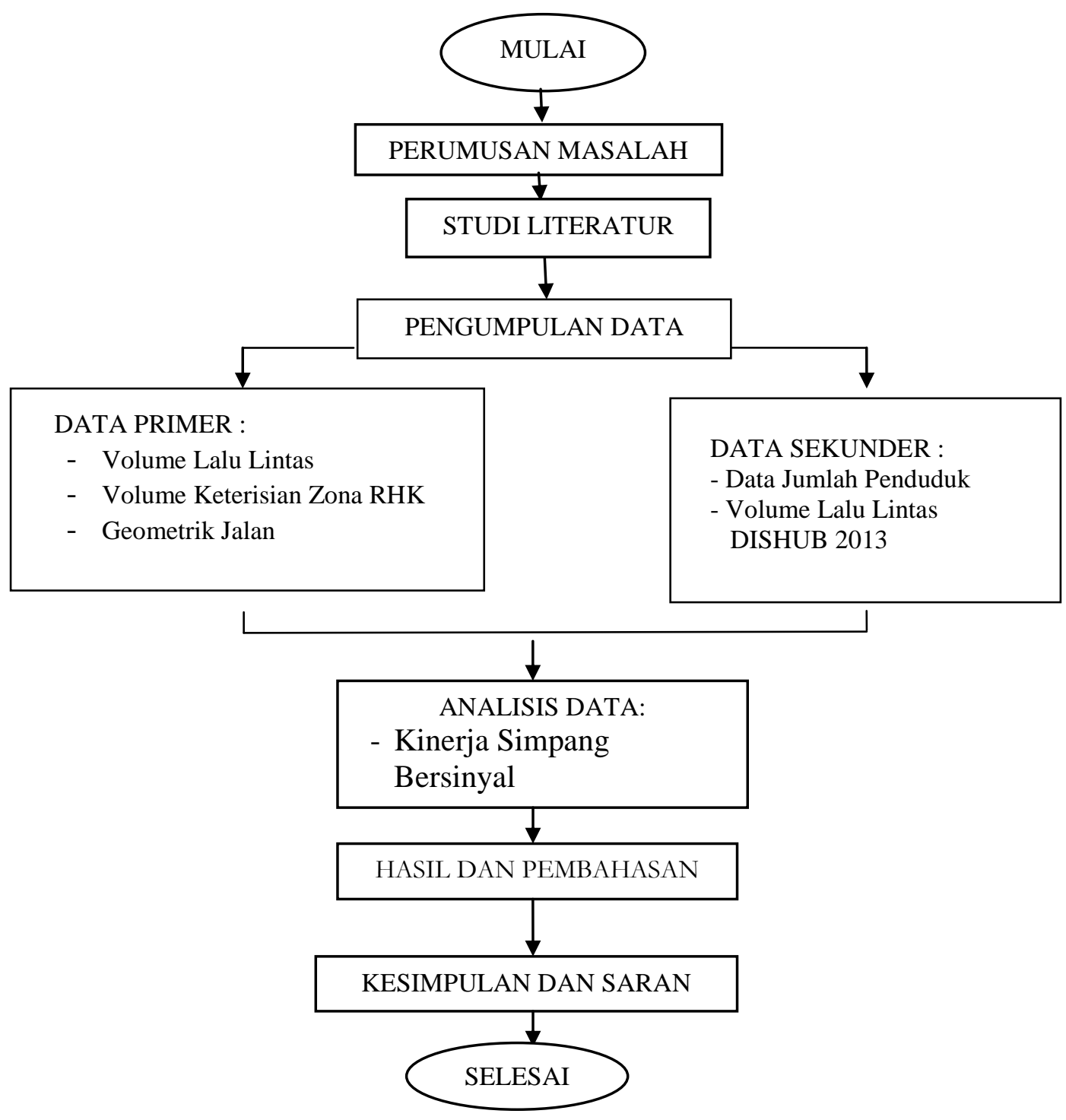

Gambar 2 Bagan Alir Penelitian

Pengumpulan data terdiri dari data primer yaitu data di lapangan sedangkan data sekunder yaitu data dari instansi Badan Pusat Statistik dan Dinas Perhubungan Aceh. Lalu data tersebut dianalisis berdasarkan studi literatur yang 
diambil berdasarkan tinjauan penelitian yang ada. Hasil dan pembahasan yang didapat pada nantinya ialah kita dapat mengetahui kelayakan zona RHK berdasarkan tingkat keterisian terhadap kinerja persimpangan bersinyal tersebut yang dilihat dari derajat kejenuhan. Kesimpulan dan saran ialah bahwa hasil penelitian ini dapat menjadi acuan evaluasi zona ruang henti khusus pada simpang bersinyal di Kota Banda Aceh untuk pemerintah setempat agar dapat membuat menjadi efektif sehingga bisa mengurangi kemacetan yang terjadi dan memperlancar arus lalu lintas.

\section{Hasil dan Pembahasan}

\subsection{Volume Lalu Lintas}

Penelitian ini terdiri dari dua data yaitu tahun 2013 di mana belum adanya zona RHK yang diperoleh dari Dinas Perhubungan Aceh dan tahun 2018 ketika sudah ada RHK yang diperoleh dari lapangan. Kedua data tersebut sama-sama dilakukan survei volume lalu lintas dilakukan selama 3 (tiga) hari yaitu untuk 1 (satu) hari mewakili hari libur dan 2 (dua) hari mewakili hari kerja dan dilakukan di tempat yang sama yaitu di Simpang Jambo Tape. Pelaksanaan survei samasama dilakukan pada jam sibuk pagi yaitu dari pukul $07.00-09.00 \mathrm{WIB}$, siang yaitu dari pukul 12.00 - 14.00 WIB dan sore yaitu dari pukul $16.00-18.00$ WIB. Data volume lalu lintas yang diperoleh dengan mencatat semua jenis kendaraan yang melintasi titik pias pengamatan dalam interval waktu 15 menit, kemudian diekivalensikan ke dalam Satuan Kendaraan Ringan (SKR), yaitu dengan cara mengalikan jumlah tiap-tiap jenis kendaraan dengan angka ekivalensi dari masingmasing jenis kendaraan (EKR) yang bersumber dari PKJI (2014).

Berdasarkan hasil pengamatan di lapangan maka didapatkan hasil survei lalu lintas di Simpang Jambo Tape pada tahun 2018 di Lapangan dan dibandingkan dengan tahun 2013 yang didapat dari Dinas Perhubungan Aceh. Perbandingan dilakukan dengan tujuan untuk mengetahui bagaimana kinerja simpang bersinyal Jambo Tape ketika belum adanya RHK tahun 2013 dan setelaha adanya RHK tahun 2018. Sehingga kita tahu nilai kinerja simpang bersinyal dari adanya RHK tersebut. Hasil volume lalu lintas perbandingan diperlihatkan pada Gambar 3

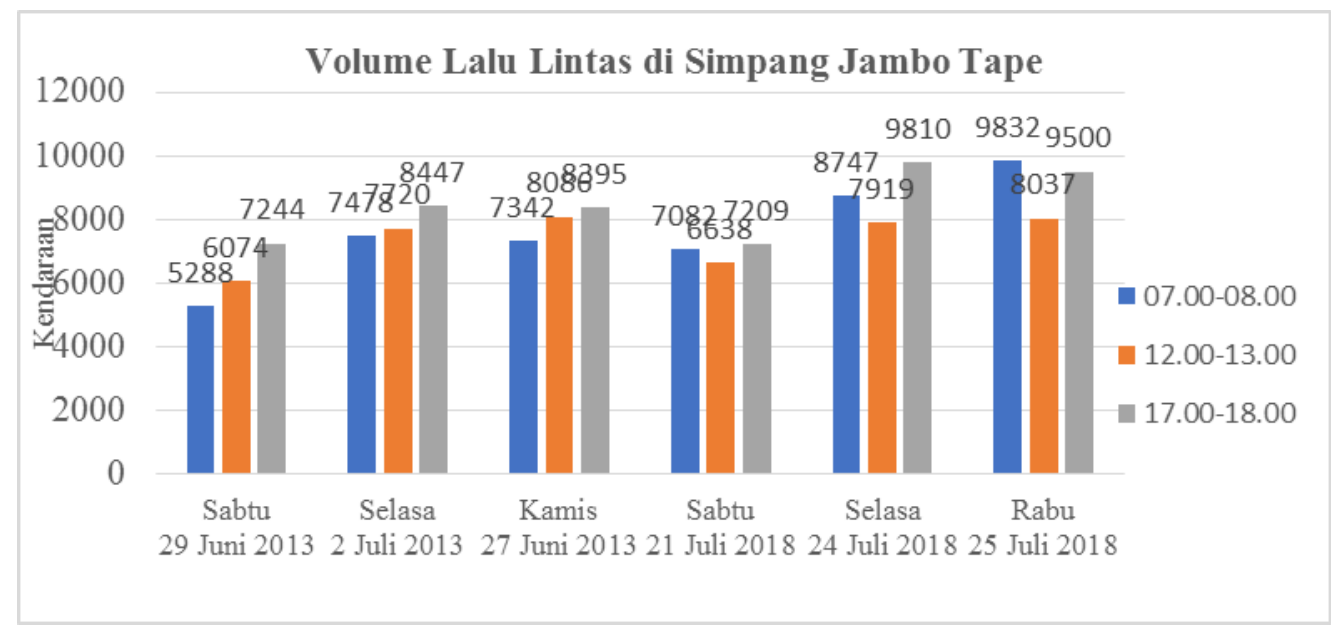

Gambar 3 Grafik Fluaktuasi Volume Lalu Lintas di Simpang Jambo Tape

Tinjauan kelayakan ruang henti khusus (rhk) berdasarkan tingkat keterisian di Simpang bersinyal kota banda aceh - Herri Arnanda, Renni Anggraini, Yusria Darma 


\subsection{Derajat Kejenuhan}

Derajat kejenuhan digunakan sebagai faktor utama dalam penentuan tingkat kinerja simpang bersinyal dengan nilai derajat kejenuhan tidak boleh melebihi 0,85 (PKJI, 2014). Sebelum mendapat nilai derajat kejenuhan maka harus dicari nilai arus lalu lintas (Q) yang didapat di lapangan lalu direkapitulasi berdasarkan jumlah kendaraan dengan masing-masing jenisnya, dikalikan dengan angka ekivalensi kendaraan ringan (EKR) untuk diubah kedalam waktu satu jam (skr/jam). Kemudian mencari nilai kapasitas (C) yang diperoleh dari hasil perkalian arus jenuh dasar dengan waktu hijau dan dibagi dengan waktu siklus setelah penyesuain seperti persamaan sebagai berikut:

$$
C=S x \frac{H}{C}
$$

Sedangkan untuk Derajat kejenuhan (Dj) untuk Simpang Jambo Tape masing-masing lengan diperoleh dari hasil perbandingan antara volume dan kapasitas. Seperti pada persamaan sebagai berikut:

$$
D j=\frac{Q}{C}
$$

Untuk hasil derajat kejenuhan dibawah ini ialah hasil perwakilan dari jamjam puncak tertinggi yang mewakili hari libur dan hari kerja selama tiga hari di lapangan untuk masing-masing lengan simpang baik pada tahun 2013 dimana belum ada RHK dan tahun 2018 ketika telah adanya RHK seperti pada Tabel 2 sampai Tabel 4.

\begin{tabular}{|c|c|c|c|c|c|c|c|c|}
\hline \multirow{2}{*}{$\begin{array}{l}\text { Kode } \\
\text { Pendekat }\end{array}$} & \multirow{2}{*}{$\begin{array}{l}\text { Tahun } \\
2013\end{array}$} & $\begin{array}{l}\text { Arus lalu } \\
\text { lintas }\end{array}$ & Kapasitas & $\begin{array}{c}\text { Derajat } \\
\text { kejenuhan }\end{array}$ & \multirow{2}{*}{$\begin{array}{c}\text { Tahun } \\
2018\end{array}$} & $\begin{array}{c}\text { Arus lalu } \\
\text { lintas }\end{array}$ & Kapasitas & $\begin{array}{c}\text { Derajat } \\
\text { kejenuhan }\end{array}$ \\
\hline & & $\begin{array}{c}\mathbf{Q} \\
\text { (skr/jam) }\end{array}$ & $\begin{array}{c}\mathrm{C} \\
\text { (skr/jam) }\end{array}$ & Dj & & $\begin{array}{c}\mathbf{Q} \\
\text { (skr/jam) }\end{array}$ & $\begin{array}{c}\mathrm{C} \\
\text { (skr/jam) }\end{array}$ & Dj \\
\hline Utara & Sabtu & 426 & 425 & 1,00 & \multirow{4}{*}{$\begin{array}{c}\text { Sabtu } \\
21 \text { Juli } \\
\text { 2018 }\end{array}$} & 475 & 309 & 1,54 \\
\hline Timur & 29 & 1.557 & 943 & 1,65 & & 1.301 & 1.095 & 1,19 \\
\hline Selatan & Juni & 1.141 & 1.114 & 1,02 & & 743 & 1.276 & 0,58 \\
\hline Barat & 2013 & 1.132 & 1.036 & 1,09 & & 755 & 1.606 & 0,47 \\
\hline
\end{tabular}

Tabel 2 Derajat kejenuhan ketika jam puncak pagi hari pukul 16.00-18.00 WIB 
Tabel 3 Derajat kejenuhan ketika jam puncak pagi hari pukul 07.00-09.00 WIB

\begin{tabular}{|c|c|c|c|c|c|c|c|c|}
\hline $\begin{array}{l}\text { Kode } \\
\text { Pendekat }\end{array}$ & $\begin{array}{c}\text { Tahun } \\
2013\end{array}$ & $\begin{array}{c}\text { Arus lalu } \\
\text { lintas } \\
\mathbf{Q} \\
\text { (skr/jam) }\end{array}$ & $\begin{array}{c}\text { Kapasitas } \\
\mathbf{C} \\
\text { (skr/jam) }\end{array}$ & $\begin{array}{c}\text { Derajat } \\
\text { kejenuhan } \\
\text { Dj }\end{array}$ & $\begin{array}{c}\text { Tahun } \\
2018\end{array}$ & $\begin{array}{c}\text { Arus lalu } \\
\text { lintas } \\
\mathbf{Q} \\
\text { (skr/jam) }\end{array}$ & $\begin{array}{c}\text { Kapasitas } \\
\mathbf{C} \\
\text { (skr/jam) }\end{array}$ & $\begin{array}{c}\text { Derajat } \\
\text { kejenuhan } \\
\text { Dj }\end{array}$ \\
\hline Utara & & 144 & 425 & 0,34 & & 286 & 309 & 0,92 \\
\hline $\begin{array}{l}\text { Timur } \\
\text { Selatan }\end{array}$ & $\begin{array}{c}\text { Selasa } \\
\text { 02 Juli } \\
2013\end{array}$ & $\begin{array}{l}863 \\
638\end{array}$ & $\begin{array}{c}937 \\
1.158\end{array}$ & $\begin{array}{l}0,92 \\
0,55\end{array}$ & $\begin{array}{c}\text { Selasa } \\
24 \text { Juli } \\
2018\end{array}$ & $\begin{array}{l}1.606 \\
1.183\end{array}$ & $\begin{array}{l}1.112 \\
1.309\end{array}$ & $\begin{array}{l}1,44 \\
0,90\end{array}$ \\
\hline Barat & & 558 & 1.010 & 0,55 & & 955 & 1.600 & 0,60 \\
\hline
\end{tabular}

Tabel 4. Derajat kejenuhan ketika jam puncak pagi hari pukul 07.00-09.00 WIB

\begin{tabular}{|c|c|c|c|c|c|c|c|c|}
\hline $\begin{array}{l}\text { Kode } \\
\text { Pendekat }\end{array}$ & $\begin{array}{c}\text { Tahun } \\
2013\end{array}$ & $\begin{array}{c}\text { Arus lalu } \\
\text { lintas } \\
\mathbf{Q} \\
\text { (skr/jam) }\end{array}$ & $\begin{array}{c}\text { Kapasitas } \\
\text { C } \\
\text { (skr/jam) }\end{array}$ & $\begin{array}{c}\text { Derajat } \\
\text { kejenuhan } \\
\text { Dj }\end{array}$ & $\begin{array}{c}\text { Tahun } \\
2018\end{array}$ & $\begin{array}{c}\text { Arus lalu } \\
\text { lintas } \\
\mathbf{Q} \\
\text { (skr/jam) }\end{array}$ & $\begin{array}{c}\text { Kapasitas } \\
\text { C } \\
\text { (skr/jam) }\end{array}$ & $\begin{array}{c}\text { Derajat } \\
\text { kejenuhan } \\
\text { Dj }\end{array}$ \\
\hline Utara & Kamis & 221 & 430 & 0,51 & \multirow{3}{*}{$\begin{array}{c}\text { Rabu } \\
25 \text { Juli } \\
2018\end{array}$} & 472 & 313 & 1,51 \\
\hline Timur & 27 & 921 & 940 & 0,98 & & 1.592 & 1.110 & 1,43 \\
\hline $\begin{array}{c}\text { Selatan } \\
\text { Barat }\end{array}$ & $\begin{array}{c}\text { Juni } \\
2013\end{array}$ & $\begin{array}{c}1.438 \\
479\end{array}$ & $\begin{array}{c}1.098 \\
972\end{array}$ & $\begin{array}{l}1,31 \\
0,49\end{array}$ & & $\begin{array}{c}1.139 \\
955\end{array}$ & $\begin{array}{l}1.307 \\
1.600\end{array}$ & $\begin{array}{l}0,87 \\
0,60\end{array}$ \\
\hline
\end{tabular}

\subsection{Ruang Henti Khusus (RHK)}

Dalam menilai kelayakan atau tidaknya RHK di simpang bersinyal ialah dengan cara seberapa berhasil tingkat keterisian RHK tersebut telah diterapkan oleh sepeda motor. Indikator keberhasilan Ruang Henti Khusus (RHK) adalah seberapa besar tingkat keterisian RHK pada saat nyala lampu merah oleh sepeda motor terhadap kapasitas maksimal sepeda motor yang dapat ditampung RHK. Dalam mencari kapasitas RHK ialah perbandingan antara luas dari zona RHK dengan dimensi dari sepeda motor, seperti pada persamaan sebagai berikut:

$$
C=\frac{A}{D}
$$

Tingkat keterisian RHK diperoleh dari hasil perbandingan antara rata-rata jumlah sepeda motor yang ada dalam zona RHK dan kapasitas dari RHK. Kelayakan RHK dilihat dari berapa persen keterisian yang ditampung zona RHK oleh sepeda motor pada setiap simpang seperti persamaan sebagai berikut:

$$
D C=\frac{R}{C} x 100 \%
$$


Tabel 5 Tingkat keterisian RHK hanya oleh sepeda motor Tingkat keterisian RHK terhadap kapasitas

Kategori penilaian

\begin{tabular}{cc}
\hline$\geq 80 \%$ & RHK berhasil diterapkan \\
$60 \%-79 \%$ & RHK cukup berhasil diterapkan \\
$<60 \%$ & RHK kurang berhasil diterapkan \\
\hline
\end{tabular}

Keterisian Ruang Henti Khusus (RHK) untuk Simpang Jambo Tape masing-masing lengan ialah hasil perwakilan dari jam-jam puncak tertinggi yang mewakili hari libur dan hari kerja selama tiga hari selama tiga hari dapat dilihat pada Tabel 6 sampai Tabel 8.

Tabel 6. RHK ketika jam puncak sore hari pukul 16.00-18.00 WIB

\begin{tabular}{|c|c|c|c|c|c|c|c|}
\hline \multirow[t]{2}{*}{$\begin{array}{c}\text { Kode } \\
\text { Pendekat }\end{array}$} & \multicolumn{3}{|c|}{$\begin{array}{l}\text { Volume Kendaraan di } \\
\text { Simpang Jambo Tape }\end{array}$} & \multirow[t]{2}{*}{$\begin{array}{c}\text { Kapasitas } \\
\text { CRHK }\end{array}$} & \multirow{2}{*}{$\begin{array}{l}\text { Rata-rata } \\
\text { Sepeda } \\
\text { Motor di } \\
\text { RHK }\end{array}$} & \multirow[t]{2}{*}{$\begin{array}{c}\text { Keterisian } \\
\text { (DC) } \%\end{array}$} & \multirow[t]{2}{*}{$\begin{array}{l}\text { Kategori } \\
\text { Penilaian }\end{array}$} \\
\hline & $\mathrm{HV}$ & LV & MC & & & & \\
\hline Utara & 1 & 328 & 969 & 23 & 16 & 69 & Cukup \\
\hline Timur & 15 & 1.035 & 1.644 & 33 & 17 & 52 & Kurang \\
\hline Selatan & 7 & 547 & 1.246 & 34 & 10 & 31 & Kurang \\
\hline Barat & 6 & 630 & 781 & 34 & 10 & 30 & Kurang \\
\hline
\end{tabular}

Tabel 7 RHK ketika jam puncak pagi hari pukul 07.00-09.00 WIB

\begin{tabular}{cccccccc}
\hline \multirow{2}{*}{$\begin{array}{c}\text { Kode } \\
\text { Pendekat }\end{array}$} & \multicolumn{2}{c}{ Volume Kendaraan di } & \multirow{2}{*}{$\begin{array}{c}\text { Kapasitas } \\
\text { Simpang Jambo Tape }\end{array}$} & \begin{tabular}{c} 
Rata-rata \\
CRHK \\
\cline { 2 - 4 } Sepeda \\
Motor di \\
RHK
\end{tabular} & $\begin{array}{c}\text { Keterisian } \\
\text { (DC) } \%\end{array}$ & $\begin{array}{c}\text { Kategori } \\
\text { Penilaian }\end{array}$ \\
\hline Utara & 0 & 212 & 491 & 23 & 8 & 35 & Kurang \\
Timur & 6 & 1.212 & 2.577 & 33 & 16 & 49 & Kurang \\
Selatan & 9 & 798 & 2.487 & 34 & 16 & 48 & Kurang \\
Barat & 14 & 710 & 1.513 & 34 & 17 & 50 & Kurang \\
\hline
\end{tabular}

Tabel 8 RHK ketika jam puncak pagi hari pukul 07.00-09.00 WIB

\begin{tabular}{|c|c|c|c|c|c|c|c|}
\hline \multirow[t]{2}{*}{$\begin{array}{c}\text { Kode } \\
\text { Pendekat }\end{array}$} & \multicolumn{3}{|c|}{$\begin{array}{l}\text { Volume Kendaraan di } \\
\text { Simpang Jambo Tape }\end{array}$} & \multirow[t]{2}{*}{$\begin{array}{c}\text { Kapasitas } \\
\text { CRHK }\end{array}$} & \multirow{2}{*}{$\begin{array}{l}\text { Rata-rata } \\
\text { Sepeda } \\
\text { Motor di } \\
\text { RHK } \\
\end{array}$} & \multirow[t]{2}{*}{$\begin{array}{l}\text { Keterisian } \\
\text { (DC) } \%\end{array}$} & \multirow[t]{2}{*}{$\begin{array}{l}\text { Kategori } \\
\text { Penilaian }\end{array}$} \\
\hline & $\mathrm{HV}$ & LV & $\mathrm{MC}$ & & & & \\
\hline Utara & 0 & 369 & 684 & 34 & 9 & 41 & Kurang \\
\hline Timur & 6 & 1.212 & 2.484 & 43 & 17 & 58 & Kurang \\
\hline Selatan & 14 & 820 & 2.006 & 51 & 14 & 40 & Kurang \\
\hline Barat & 14 & 710 & 1.513 & 50 & 15 & 46 & Kurang \\
\hline
\end{tabular}

Tinjauan kelayakan ruang henti khusus (rhk) berdasarkan tingkat keterisian di Simpang bersinyal kota banda aceh - Herri Arnanda, Renni Anggraini, Yusria Darma 
Hasil yang diperoleh pada Simpang Jambo Tape baik pada tahun 2013 dan tahun 2018 selama tiga hari dimana satu hari pada hari libur dan dua hari pada hari kerja. Pada hari libur yaitu sabtu didapat pada saat volume lalu lintas tertinggi pada saat sore hari dimana untuk volumenya ialah dari $4256 \mathrm{skr} / \mathrm{jam}$ menjadi 3274 skr/jam, untuk kapasitasnya dari 3517 skr/jam menjadi 4287 skr/jam, untuk derajat kejenuhan dari 1,21 menjadi 0,76 dan rata-rata tingkat keterisian ruang henti khususnya hanya $46 \%$ dimana artinya kurang berhasil diterapkan. Untuk hari kerja yaitu hari selasa untuk volumenya ialah dari 2203 skr/jam menjadi 4030 skr/jam, untuk kapasitasnya dari 3530 skr/jam menjadi 4331 skr/jam, untuk derajat kejenuhan dari 0,62 menjadi 0,93 dan rata-rata tingkat keterisian ruang henti khususnya hanya $46 \%$ dimana artinya kurang berhasil diterapkan. Lalu untuk hari kerja lainnya yaitu hari kamis pada tahun 2013 sedangkan hari rabu pada tahun 2018 volumenya ialah dari 3509 skr/jam menjadi $4158 \mathrm{skr} / \mathrm{jam}$, untuk kapasitasnya dari $3440 \mathrm{skr} / \mathrm{jam}$ menjadi $4331 \mathrm{skr} / \mathrm{jam}$, untuk derajat kejenuhan dari 0,89 menjadi 0,96 dan rata-rata tingkat keterisian ruang henti khususnya hanya $46 \%$ dimana artinya kurang berhasil diterapkan.

\section{Kesimpulan dan Saran}

\subsection{Kesimpulan}

Pada Simpang Jambo Tape baik pada tahun 2013 dan tahun 2018 selama tiga hari dimana satu hari pada hari libur dan dua hari pada hari kerja. Pada hari libur yaitu sabtu didapat derajat kejenuhannya dari 1,21 (2013) menjadi 0,76 (2018). Untuk hari kerja yaitu hari selasa untuk derajat kejenuhan dari 0,62 (2013) menjadi 0,93 (2018). Lalu untuk hari kerja lainnya yaitu hari kamis pada tahun 2013 sedangkan hari rabu pada tahun 2018 untuk derajat kejenuhan dari 0,89 (2013) menjadi 0,96 (2018). Dan untuk rata-rata tingkat keterisian ruang henti khususnya hanya $46 \%$ dimana artinya kurang berhasil diterapkan.

\subsection{Saran}

Berikut ini diberikan beberapa saran untuk kesempurnaan penelitian diantaranya:

1. Hasil penelitian dapat menjadi acuan evaluasi zona ruang henti khusus pada simpang bersinyal di Kota Banda Aceh agar dapat menjadi efektif dalam mengurangi kemacetan yang terjadi.

2. Dapat menambah lajur khusus bagi sepeda motor untuk masuk ke dalam zona ruang henti khusus (rhk) sepeda motor sehingga dapat membuat efektif dalam penggunaan zona itu sendiri dan kenyamanan bagi pengguna jalan terutama pengendara sepeda motor.

3. Perlu penelitian hubungan dimensi ruang henti khusus (rhk) dan persentase sepeda motor terhadap total volume lalu lintas dalam rangka standarisasi/klasifikasi aplikasi di lapangan.

4. Perlu kajian lebih lanjut tentang perancangan, monitoring, evaluasi dan peraturan perundang-undangan yang mengatur ruang henti khusus (rhk) sepeda motor 


\section{Daftar Kepustakaan}

Bukhari, dan Sofyan, 2004, 'Rekayasa Lalu Lintas I', Bidang Studi Transportasi Fakultas Teknik Universitas Syiah Kuala, Banda Aceh

Dishub Aceh, 2017, Ruang Henti Khusus Kendaraan Bermotor Roda Dua (RHK), Banda Aceh, dilihat 4 September 2017, http://dishub.bandaacehkota.go.id.

Kementerian Pekerjaan Umum dan Perumahan Rakyat, 2014, 'Panduan Kapasitas Jalan Indonesia', Direktorat Jenderal Bina Marga, Jakarta

Kementerian Pekerjaan Umum dan Perumahan Rakyat, 2015, 'Pedoman Perancangan Ruang Henti Khusus (RHK) Sepeda Motor Pada Simpang Bersinyal di Kawasan Perkotaan, Direktorat Jenderal Bina Marga, Puslitbang Jalan dan Jembatan: Jakarta.

Pemerintah Kota Banda Aceh, 2017, Tim Kementerian Perhubungan Nilai Transportasi Kota Banda Aceh, banda aceh kota.go.id (diakses 20 April)

Copyright (c) herri arnanda, Renni Anggraini, Yusria Darma 